\title{
GIECTNO-SKRĘTNA UTRATA STATECZNOŚCI PODPARTYCH WIDEŁKOWO I OBCIĄŻONYCH MIMOŚRODOWO SŁUPÓW DWUTEOWYCH
}

\begin{abstract}
W pracy przedstawiono analityczną metodę wyznaczania mnożnika obciążenia krytycznego giętno-skrętnej utraty stateczności niestężonych słupów wykonanych z dwuteowników bisymetrycznych. Zależności analityczne skonstruowano w ten sposób, by były rozszerzeniem wzorów na moment krytyczny zwichrzenia zginanych belek dwuteowych. Zaletą tego podejścia jest miedzy innymi to, że możemy ocenić wpływ siły osiowej na podstawie zmiany znanych ze wzorów na moment krytyczny zwichrzenia współczynników (w tym przypadku $C_{1}$ i $D$ ). Przemieszczenie z płaszczyzny zginania jest aproksymowane za pomocą funkcji będącej kombinacją symetrycznej i antysymetrycznej postaci wyboczenia. Przykłady numeryczne pokazują dobrą zgodność rozwiązań analitycznych z wynikami otrzymanymi w programie LTBeamN. Metoda może znaleźć praktyczne zastosowanie przy wymiarowaniu metodą ogólną słupów obciążonych mimośrodowo.
\end{abstract}

Słowa kluczowe: giętno-skrętna utrata stateczności, słupy obciążone mimośrodowo, podparcie widełkowe, dwuteowniki bisymetryczne, rozwiązanie analityczne

\section{Wprowadzenie}

W przypadku wymiarowania słupów jednokierunkowo zginanych i ściskanych metodą ogólną [12] musimy wyznaczyć mnożnik obciążenia krytycznego dla giętno-skrętnej utraty stateczności. W pracy analizowano przypadki obciążenia momentami skupionymi na podporach z ewentualnym jednoczesnym obciążeniem równomiernie rozłożonym w przęśle. Omówienie literatury w której analizowano moment krytyczny zwichrzenia dla prostszych schematów statycznych przedstawiono np. w [1,7]. Natomiast w literaturze zestawionej na końcu tego opracowania w zasadzie zawarto pozycje, które starają się łączyć prostotę wzo-

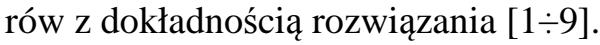

Otrzymane rozwiązania porównano z wynikami MES (LTBeamN [14]). W tym programie pręt jest dzielony na 100 elementów skończonych. W przypadku podziału na 200 elementów wynik jest ten sam (z dokładnością do 0,001).

${ }^{1}$ Roman Bijak, Politechnika Świętokrzyska, Aleja Tysiąclecia P.P. 7, 25-314 Kielce, r.bijak@wp.pl 
W prezentowanej pracy wyprowadzono odpowiednie zależności analityczne uwzględniające wpływ siły osiowej w ten sposób, by były rozszerzeniem

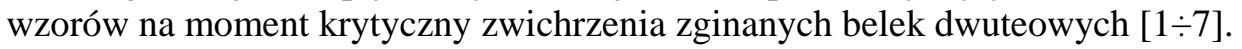
W celu poprawy dokładności rozwiązania, przemieszczenie z płaszczyzny zginania jest aproksymowane za pomocą funkcji będącej kombinacją symetrycznej i antysymetrycznej postaci wyboczenia (por. $[8,9]$ ). W pracy nie uwzględniano podatności połączeń, która ma istotny wpływ na utratę stateczności np. płatwi dwuteowych [11]. W przypadku słupów założenie podparcia widełkowego na końcach daje oszacowania po stronie bezpiecznej.
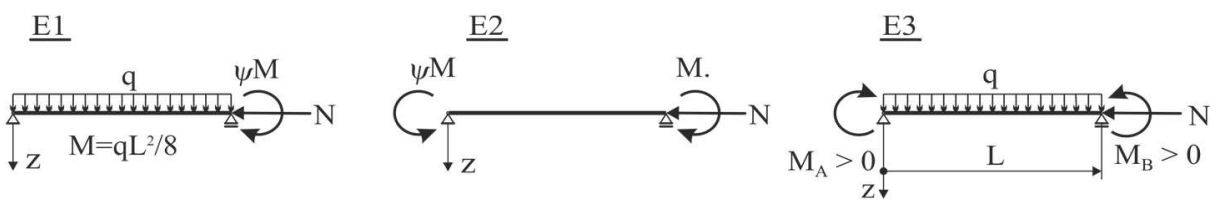

Rys. 1. Rozpatrywane przypadki obciążenia

Fig. 1. Considered load cases

Moment krytyczny zwichrzenia niestężonych belek zginanych o przekroju bisymetrycznym, podpartych widełkowo na końcach, możemy aproksymować za pomocą wzoru:

$$
\begin{aligned}
& M_{0, c r}=C_{1} \cdot N_{c r, z}\left(\sqrt{D+\left(C_{2} z_{g}\right)^{2}}+C_{2} z_{g}\right) \\
& D=\frac{I_{w}}{I_{z}}+\frac{G I_{T}}{N_{c r, z}}, \quad N_{c r, z}=\frac{\pi^{2} E I_{z}}{L^{2}}
\end{aligned}
$$

gdzie: $C_{1}$ - współczynnik zależny od rozkładu momentu zginającego,

$C_{2}$ - współczynnik zależny od $C_{1}$ i rozkładu obciążenia poprzecznego,

$z_{g}$ - współrzędna przyłożenia obciążenia poprzecznego,

$E$, $G$-odpowiednio moduł sprężystości podłużnej i poprzecznej,

$I_{w}, I_{\mathrm{T}}-$ moment bezwładności wycinkowy i skręcania St. Venanta,

$I_{z}$ - moment bezwładności względem osi $z$,

$L$ - rozpiętość belki.

W literaturze niemieckiej [6] wzór (1) jest nieco inaczej zapisany:

$$
C_{1}=\zeta, \quad C_{2}=0,5, \quad D=c^{2}, \quad \frac{G I_{T}}{N_{c r, z}} \approx 0,039 \cdot \frac{I_{T} L^{2}}{I_{z}}
$$

Przyjęcie stałej $C_{2}$ wg wzoru (3b) upraszcza obliczenia. Jest jednak niepoprawne $\mathrm{w}$ przypadku schematów statycznych $\mathrm{z}$ obciążeniem poprzecznym i momentami skupionymi na podporach [5]. 


\section{Moment krytyczny zwichrzenia zginanych belek dwuteowych}

Warunek giętno-skrętnej utraty stateczności zginanych belek wykonanych z dwuteowników bisymetrycznych możemy zapisać w formie [3]:

$$
\begin{aligned}
\delta I_{b 1}= & \int_{L}\left(E I_{z} v^{(2)} \delta v^{(2)}+G I_{T} \varphi^{(1)} \delta \varphi^{(1)}+E I_{w} \varphi^{(2)} \delta \varphi^{(2)}\right) d x+ \\
& +\int_{L} M_{y}^{b}(x)\left(v^{(2)} \delta \varphi+\varphi \delta v^{(2)}\right) d x+\int_{L} q_{z}^{b} z_{g} \varphi \delta \varphi d x=0
\end{aligned}
$$

gdzie: $f^{(\mathrm{k})}=\mathrm{d}^{\mathrm{k}} f / \mathrm{d} S^{\mathrm{k}}-k$-ta pochodna po współrzędnej $x$,

$v(x)$ - przemieszczenie wzdłuż osi $y$,

$\varphi(x)$ - kąt skręcenia przekroju.

Górny indeks $b$ odnosi się do stanu krytycznego:

$$
M_{y}^{b}(x)=\mu_{c r} M_{y}(x), \quad q_{z}^{b}=\mu_{c r} q
$$

gdzie: $M_{y}(x)$ - rozkład momentu zginającego po długości elementu,

$\mu_{c r}-$ mnożnik obciążenia krytycznego,

$q$ - obciążenie rozłożone skierowane wzdłuż osi $z$.

Całkując przez części (4) otrzymujemy układ równań różniczkowych giętno-skrętnej utraty stateczności:

$$
\begin{aligned}
& E I_{z} v^{(4)}+M_{y}^{b} \varphi^{(2)}=0 \\
& M_{y}^{b} v^{(2)}+q_{z}^{b} \varphi+E I_{w} \varphi^{(4)}-G I_{T} \varphi^{(2)}=0
\end{aligned}
$$

Wykonując dwukrotne całkowanie równania (6) i uwzględniając warunki brzegowe dla podparcia widełkowego otrzymujemy:

$$
v^{(2)}=-\frac{M_{y}^{b}(x)}{E I_{z}} \varphi
$$

Po podstawieniu zależności (8) do (7) redukujemy układ (6), (7) do równania różniczkowego giętno-skrętnej utraty stateczności:

$$
-\frac{\left[M_{y}^{b}(x)\right]^{2}}{E I_{z}} \varphi+q_{z}^{b} \varphi+E I_{w} \varphi^{(4)}-G I_{T} \varphi^{(2)}=0
$$

Równanie (9) jest podstawą do znalezienia przybliżonego rozwiązania analitycznego. Zostało to pokazane szczegółowo w pracach $[4,5]$. W dalszej części przedstawiono tylko wyniki potrzebne do opracowania przykładów. 
W celu oszacowania momentu krytycznego zwichrzenia wykorzystano metodę ortogonalizacyjną Bubnowa-Galerkina [3 $\div 5]$ otrzymując równanie:

$$
\begin{aligned}
& -a_{1}\left(M_{0}^{b}\right)^{2}+N_{c r, z} a_{2} z_{\mathrm{g}}\left(M_{0}^{b}\right)+N_{c r, z}^{2} D=0 \\
& a_{1}=\frac{2}{M_{0}^{2} L} \int_{0}^{L} M_{y}^{2}(x) \sin ^{2} \frac{\pi x}{L} d x, \quad a_{2}=\frac{q L^{2}}{M_{0} \pi^{2}}
\end{aligned}
$$

gdzie: $M_{0}{ }^{b}=\mu_{c r} M_{0}-$ krytyczna wartość momentu $M_{0}$,

$M_{0}$ - maksymalna wartość bezwzględna momentu zginającego

$$
\left(\max \left|M_{\mathrm{y}}(x)\right| 0 \leq x \leq L\right) .
$$

Rozwiązanie równania kwadratowego (10) można zapisać w postaci wzoru (1) z następującymi parametrami $C_{1}, C_{2}[4,5]$ :

$$
\begin{aligned}
& C_{1}=\frac{1}{\sqrt{a_{1}}} \\
& C_{2}=C_{1} \frac{a_{2}}{2}
\end{aligned}
$$

Dla prostych schematów obciążeń współczynnik $C_{1}$ wyznaczamy bezpośrednio ze wzorów (11a), (12). W tabeli 1. zestawiono aproksymację współczynników $C_{1}, C_{2}$ dla schematów statycznych rozpatrywanych w dalszej części pracy.

Tabela 1. Współczynniki $C_{1}, C_{2}$ dla wybranych schematów obciążenia (rys. 1.)

Table 1. Coefficients $C_{1}, C_{2}$ for selected load cases (fig. 1.)

\begin{tabular}{|c|c|c|c|}
\hline \multirow{2}{*}{ Wsp. } & \multicolumn{2}{|c|}{ Schemat statyczny E1 (rys. 1) } & Schemat statyczny E2 (rys. 1) \\
\cline { 2 - 4 } & $0 \leq \psi \leq 0,69$ & $0,69 \leq \psi \leq 1$ & $0 \leq \psi \leq 1$ \\
\hline$C_{1}$ & $1,13+0,10 \psi$ & $-1,25+3,5 \psi$ & $1,77-1,04 \psi+0,27 \psi^{2} \quad\left(\right.$ lecz $\left.C_{1} \leq 2,6\right)$ \\
\hline$C_{2}$ & $0,41 C_{1} /(1-\psi / 4)^{2}$ & $0,41 C_{1} / \psi$ & 0 \\
\hline
\end{tabular}

W ogólnym przypadku (schemat statyczny E3, rys. 1.) współczynnik $C_{1}$ możemy aproksymować za pomocą wzoru:

$$
C_{1}=\sqrt{\frac{21 M_{0}^{2}}{M_{0}^{2}+6 M_{2}^{2}+8 M_{3}^{2}+6 M_{4}^{2}}}
$$

gdzie: $M_{2}, M_{3}, M_{4}-$ momenty zginające odpowiednio dla $x=L / 4, L / 2,3 L / 4$. 


\section{Wpływ siły osiowej na giętno-skrętną utratę stateczności}

Uwzględniając (4) warunek giętno-skrętnej utraty stateczności jednokierunkowo zginanych i ściskanych słupów wykonanych z dwuteowników bisymetrycznych możemy zapisać w formie:

$$
\delta \Pi_{b 2}=\delta \Pi_{b 1}-\int_{L} N^{b}\left(v^{(1)} \delta^{(1)}+i_{p}^{2} \varphi^{(1)} \delta \varphi^{(1)}\right) d x=0
$$

gdzie: $N^{b}=\mu_{c r} N-$ krytyczna wartość siły ściskającej,

$i_{p}$ - biegunowy promień bezwładności.

Całkując przez części (15) otrzymujemy układ równań różniczkowych giętno-skrętnej utraty stateczności:

$$
\begin{aligned}
& E I_{z} v^{(4)}+M_{y}^{b} \varphi^{(2)}+N^{b} v^{(2)}=0 \\
& M_{y}^{b} v^{(2)}+q_{z}^{b} \varphi+E I_{w} \varphi^{(4)}-G I_{T} \varphi^{(2)}+N^{b} i_{p}^{2} \varphi^{(2)}=0
\end{aligned}
$$

Wykonując dwukrotne całkowanie równania (16) i uwzględniając warunki brzegowe dla podparcia widełkowego otrzymujemy (por. (8)):

$$
v^{(2)}=-\frac{M_{y}^{b}(x)}{E I_{z}} \varphi-\frac{N^{b}}{E I_{z}} v
$$

Po podstawieniu zależności (18) do (17) otrzymujemy zmodyfikowany układ równań różniczkowych giętno-skrętnej utraty stateczności:

$$
\begin{aligned}
& E I_{z} v^{(2)}+M_{y}^{b} \varphi+N^{b} v=0 \\
& -\frac{\left[M_{y}^{b}(x)\right]^{2}}{E I_{z}} \varphi-N^{b} \frac{M_{y}^{b}(x)}{E I_{z}} v+q_{z}^{b} \varphi+E I_{w} \varphi^{(4)}-G I_{T} \varphi^{(2)}+N^{b} i_{p}^{2} \varphi^{(2)}=0
\end{aligned}
$$

Przemieszczenia założono w postaci:

$$
\varphi(x)=A \sin \left(\frac{\pi x}{L}\right), \quad v(x)=B_{1} \sin \left(\frac{\pi x}{L}\right)+B_{2} \sin \left(\frac{2 \pi x}{L}\right)
$$

W celu oszacowania momentu krytycznego zwichrzenia wykorzystano metodę ortogonalizacyjną Bubnowa-Galerkina. Wyznaczono równanie kwadratowe:

$$
-\bar{a}_{1}\left(M_{0}^{b}\right)^{2}+N_{c r, z} a_{2} \mathrm{z}_{\mathrm{g}}\left(M_{0}^{b}\right)+N_{c r, z}^{2} \bar{D}=0
$$

Współczynnik $a_{2}$ we wzorze (22) jest taki sam jak w (11). Pozostałe parametry uwzględniają wpływ siły osiowej: 


$$
\begin{aligned}
& \bar{a}_{1}=\frac{1}{C_{1}^{2}}+\frac{\delta_{N}}{1-\delta_{N}}\left(g_{1}\right)^{2}+\frac{\delta_{N}}{4-\delta_{N}}\left(g_{2}\right)^{2}, \quad \bar{D}=D-\delta_{N} i_{p}^{2}, \quad \delta_{N}=\frac{N^{b}}{N_{c r, z}} \\
& g_{1}=\frac{M_{\mathrm{A}}+M_{\mathrm{B}}}{2 M_{0}}+\frac{q L^{2}\left(\pi^{2}+3\right)}{12 M_{0} \pi^{2}}, \quad g_{2}=\frac{16\left(M_{\mathrm{A}}-M_{\mathrm{B}}\right)}{9 M_{0} \pi^{2}}
\end{aligned}
$$

gdzie: $M_{\mathrm{A}}, M_{\mathrm{B}}-$ momenty skupione na podporach wg rys. 1 .

Moment krytyczny możemy zapisać analogicznie do (1):

$$
\begin{aligned}
& M_{0}^{b}\left(N^{b}\right)=\bar{C}_{1} \cdot N_{c r, z}\left(\sqrt{\bar{D}+\left(\bar{C}_{2} z_{g}\right)^{2}}+\bar{C}_{2} z_{g}\right) \\
& \bar{C}_{1}=\frac{1}{\sqrt{\bar{a}_{1}}}, \quad \bar{C}_{2}=\bar{C}_{1} \frac{a_{2}}{2}, \quad \mu_{c r}=\frac{M_{0}^{b}}{M_{0}}=\frac{N^{b}}{N}
\end{aligned}
$$

\section{Wyniki obliczeń}

Mnożnik obciążenia krytycznego $\mu_{c r}$ wyznaczamy iteracyjnie. Najpierw zakładamy jego wartość początkową np. $\mu_{c r, 1}=3$. Na jej podstawie wyznaczamy $N_{1}^{b}=\mu_{c r, 1} N$ oraz $M_{01}{ }^{b}\left(N_{1}^{b}\right)$ wg (25). Następnie określamy $\mu_{c r}=M_{01}{ }^{b} / M_{0}$. Obliczenia powtarzamy do momentu, gdy $\mu_{c r, i} \approx \mu_{c r}$. Wygodnie jest opracować odpowiedni arkusz kalkulacyjny.

$\mathrm{W}$ tabeli 2. porównano rozwiązanie analityczne z wynikami MES w przypadku słupa wykonanego z HEA 400 o długości $L=8,5 \mathrm{~m}$ dla schematu statycznego E2 (rys. 1.) $\left(M_{c r}, M_{0}{ }^{b}\right.$ przedstawiono w kNm, $\left.N_{0}{ }^{b} \mathrm{w} \mathrm{kN}, D \mathrm{w} \mathrm{cm}{ }^{2}\right)$. Obliczeniowa siła ściskająca wynosi $N_{E d}=600 \mathrm{kN}$, obliczeniowy moment skupiony $M_{y, E d}=350 \mathrm{kNm}$.

Tabela 2. Liniowy rozkład momentu zginającego (przypadek E2, rys. 1.)

Table 2. Linear bending moment distribution (case E2, fig. 1.)

\begin{tabular}{|c|c|c|c|c|c|c|c|c|c|c|}
\hline \multirow{2}{*}{ Metoda } & \multicolumn{4}{|c|}{ Zginanie } & \multicolumn{5}{|c|}{ Zginanie ze ściskaniem } \\
\cline { 2 - 12 } & $\psi$ & $C_{1}$ & $C_{2}$ & $M_{c r}$ & $C_{1}$ & $C_{2}$ & $D$ & $\mu_{c r}$ & $M_{0}{ }^{b}$ & $N_{0}{ }^{b}$ \\
\hline LTBeamN & 1 & - & - & 765,2 & - & - & - & 1,59 & 557 & 954 \\
\hline wzór (25) & 1 & 1 & 0 & 765,2 & 0,784 & 0 & 835,2 & 1,58 & 556 & 948 \\
\hline LTBeamN & 0 & - & - & 1401 & - & - & - & 2,40 & 840 & 1440 \\
\hline wzór (25) & 0 & 1,77 & 0 & 1354 & 1,220 & 0 & 766,8 & 2,38 & 830 & 1428 \\
\hline LTBeamN & $-0,6$ & - & - & 2040 & - & - & - & 3,22 & 1127 & 1932 \\
\hline wzór (25) & $-0,6$ & 2,49 & 0 & 1906 & 1,744 & 0 & 695,1 & 3,22 & 1130 & 1906 \\
\hline
\end{tabular}


W Tabeli 3 porównano rozwiązanie analityczne z wynikami MES w przypadku słupa wykonanego z HEA 400 o długości $L=8,5 \mathrm{~m}$ dla schematu statycznego E1 (rys. 1). Obliczeniowa siła ściskająca wynosi $N_{E d}=600 \mathrm{kN}$. Obciążenie równomiernie rozłożone $q_{E d}=40 \mathrm{kN} / \mathrm{m}$ jest przyłożone do górnej półki.

Tabela 3. Obciążenie wg wykresu E1 (rys. 1.)

Table 3. Load according to E1 diagram (fig. 1.)

\begin{tabular}{|c|c|c|c|c|c|c|c|c|c|c|}
\hline \multirow{2}{*}{ Metoda } & \multicolumn{5}{|c|}{ Zginanie } & \multicolumn{6}{|c|}{ Zginanie ze ściskaniem } \\
\cline { 2 - 12 } & $\psi$ & $C_{1}$ & $C_{2}$ & $M_{c r}$ & $C_{1}$ & $C_{2}$ & $D$ & $\mu_{c r}$ & $M_{0}{ }^{b}$ & $N_{0}{ }^{b}$ \\
\hline LTBeamN & 0 & - & - & 652,3 & - & - & - & 1,42 & 515,1 & 856 \\
\hline wzór (25) & 0 & 1,13 & 0,46 & 650,8 & 0,919 & 0,373 & 848,8 & 1,42 & 513,7 & 852 \\
\hline LTBeamN & 0,8 & - & - & 738,1 & - & - & - & 1,91 & 552,7 & 1148 \\
\hline wzór (25) & 0,8 & 1,55 & 0,79 & 734,9 & 1,255 & 0,643 & 802,7 & 1,96 & 568,7 & 1176 \\
\hline LTBeamN & 1 & - & - & 1003 & - & - & - & 2,07 & 748,6 & 1243 \\
\hline wzór (25) & 1 & 2,25 & 0,92 & 993,5 & 1,689 & 0,685 & 795 & 2,05 & 740,3 & 1230 \\
\hline
\end{tabular}

\section{Przykłady wymiarowania wg metody ogólnej}

W przypadku wymiarowania słupów mimośrodowo ściskanych metodą ogólną [12] musimy wyznaczyć mnożnik obciążenia krytycznego dla giętnoskrętnej utraty stateczności:

$$
\alpha_{c r, o p}=\mu_{c r}
$$

Za pomocą analizy geometrycznie nieliniowej z uwzględnieniem imperfekcji geometrycznych wyznaczamy $M_{y, E d}^{I I}$ oraz globalną smukłość względną (28a):

$$
\bar{\lambda}_{o p}=\sqrt{\frac{\alpha_{u l t, k}}{\alpha_{c r, o p}}}, \quad \frac{1}{\alpha_{u l t, k}}=\frac{N_{E d}}{N_{R k}}+\frac{M_{E d}^{I I}}{M_{y, R k}}
$$

gdzie: $N_{R k}, M_{y, R k}$ - nośność charakterystyczna przekroju krytycznego odpowiednio przy ściskaniu i zginaniu.

Na podstawie $\bar{\lambda}_{o p}$ wyznaczamy współczynniki wyboczenia i zwichrzenia:

$$
\chi_{z, o p}=\chi_{z}\left(\bar{\lambda}_{o p}\right), \quad \chi_{L T, o p}=\bar{\chi}_{L T}\left(\bar{\lambda}_{o p}\right)
$$

Jeżeli $\alpha_{u l t, k}$ wyznaczamy ze wzoru (28b) to warunek stateczności przyjmuje postać (30a). W przypadku tradycyjnej metody korzystamy ze wzoru (30b) $\left(M_{y, E d}^{I}\right.$ otrzymujemy z analizy liniowej). 


$$
w_{1}=\frac{N_{E d}}{\frac{\chi_{z, o p} N_{R k}}{\gamma_{M 1}}}+\frac{M_{E d}^{I I}}{\frac{\chi_{L T, o p} M_{y, R k}}{\gamma_{M 1}}} \leq 1, \quad w_{1}^{*}=\frac{N_{E d}}{\frac{\chi_{z} N_{R k}}{\gamma_{M 1}}}+\frac{M_{E d}^{I}}{\frac{\chi_{L T} M_{y, R k}}{\gamma_{M 1}}} \leq 1
$$

W przykładach przedstawionych poniżej porównano warunek stateczności elementu wg metody 2 i metody ogólnej [12, 13]. Maksymalny moment zginający występuje w nich nad podporą i wówczas $M_{y, E d}^{I I}=M_{y, E d}^{I}$. Pominięto sprawdzenie nośności przekroju.

\section{Przykład 1}

Rozpatrzmy słup wykonany z HEA 400 ze stali S235 o długości $L=8,5 \mathrm{~m}$ obciążony wg schematu statycznego E2 ( $\psi=0$, rys. 1.) [12]. Obliczeniowa siła ściskająca wynosi $N_{E d}=600 \mathrm{kN}$, obliczeniowy moment skupiony $M_{y, E d}=350 \mathrm{kNm}$. Nośności przekroju wynoszą: $N_{R k}=3736 \mathrm{kN}, M_{y, R k}=602 \mathrm{kNm}\left(\gamma_{M 1}=1,1\right)$. W tabeli 4. zestawiono podstawowe parametry dla warunków stateczności elementu $\left(M_{c r}\right.$ w kNm, $N_{c r, z}$ w kN). Jeżeli zastosujemy bardziej zaawansowane metody numeryczne [12], to wówczas: $\alpha_{c r, o p}=2,42, w_{1}=0,989$.

Tabela 4. Warunek stateczności elementu [12] wg metody 2 i metody ogólnej

Table 4. Stability condition for element [12] according to method 2 and general method

\begin{tabular}{|c|c|c|c|c|c|c|c|c|c|c|c|}
\hline \multicolumn{9}{|c|}{ Metoda 2 [12] } & \multicolumn{7}{c|}{ Metoda ogólna } \\
\hline$N_{\underline{c} \underline{\underline{r}} \underline{\underline{z}}}$ & $\chi_{z}$ & $M_{c r}$ & $\chi_{L T}$ & $k_{z y}$ & $w_{1}{ }^{*}$ & $\alpha_{c r, o p}$ & $\alpha_{u l t, k}$ & $\lambda_{o p}$ & $\chi_{z, o p}$ & $\chi_{L T, o p}$ & $w_{1}$ \\
\hline 2450 & 0,460 & 1414 & 1,00 & 0,89 & 0,954 & 2,40 & 1,348 & 0,749 & 0,755 & 0,844 & 0,992 \\
\hline
\end{tabular}

\section{Przykład 2}

Rozpatrzmy słup wykonany z IPE 500 ze stali S235 o długości $L=3,5 \mathrm{~m}$. Będziemy korzystać ze wzorów dla schematu E3 $\left(M_{A}=0, M_{B}=-350 \mathrm{kNm}\right)$. Obliczeniowa siła ściskająca wynosi $N_{E d}=800 \mathrm{kN}$. Obliczeniowe obciążenie rozłożone $q_{E d}=30 \mathrm{kN} / \mathrm{m}$ jest przyłożone do środka ciężkości $\left(z_{g}=0\right)$ [13]. Nośności przekroju wynoszą: $N_{R k}=2714 \mathrm{kN}, M_{y_{2} R k}=516 \mathrm{kNm}$. W tabeli 5 . zestawiono podstawowe parametry dla warunków stateczności elementu $\left(M_{c r} \mathrm{~W} \mathrm{kNm}, N_{c r, \mathrm{z}}\right.$ w kN, $\left.\gamma_{M 1}=1,0\right)$. Współczynnik $C_{1}$ wyznaczono za pomocą wzoru (14):

$$
C_{1}=\sqrt{\frac{21 \cdot 350^{2}}{350^{2}+6 \cdot 53,05^{2}+8 \cdot 129,06^{2}+6 \cdot 22805^{2}}}=2,098
$$

Następnie wyznaczamy $a_{2}$ i $C_{2}$ odpowiednio ze wzorów (11b), (13). Jeżeli skorzystamy z programu LTBeamN to wówczas: $\alpha_{c r, o p}=3,125, w_{1}=1,099$. 
Tabela 5 Warunek stateczności elementu [13] wg metody 2 i metody ogólnej

Table 5. Stability condition for element [13] according to method 2 and general method

\begin{tabular}{|c|c|c|c|c|c|c|c|c|c|c|c|}
\hline \multicolumn{9}{|c|}{ Metoda 2 [13] } & \multicolumn{9}{c|}{ Metoda ogólna } \\
\hline$N_{\underline{c}, \underline{z}}$ & $\chi_{z}$ & $M_{c r}$ & $\chi_{L T}$ & $k_{z y}$ & $w_{1}{ }^{*}$ & $\alpha_{c r, o p}$ & $\alpha_{u l t, k}$ & $\lambda_{o p}$ & $\chi_{z, o p}$ & $\chi_{L T, o p}$ & $w_{1}$ \\
\hline 3624 & 0,683 & 2127 & 1,00 & 0,847 & 1,006 & 3,08 & 1,028 & 0,578 & 0,849 & 0,899 & 1,102 \\
\hline
\end{tabular}

\section{Uwagi i wnioski}

Prezentowana metoda pozwala na automatyczne wymiarowanie w arkuszu kalkulacyjnym słupów mimośrodowo ściskanych wg metody ogólnej. W rozpatrywanych przykładach otrzymano stosunkowo małe błędy aproksymacji mnożnika obciążenia krytycznego wyznaczonego ze wzorów $(23 \div 26)$. Przedstawione przykłady są jednak stosunkowo proste. Żeby stosować ją w praktyce projektowej potrzebne są dalsze analizy [15].

Zarówno w przypadku prezentowanej metody jak i programu LTBeamN istnieje możliwość rozpatrywania obciążenia dwuparametrowego podobnie jak w pracy [10]. Jeżeli np. $N^{b} / N=\mu_{c r, N}, M_{0}{ }^{b} / M_{0}=\mu_{c r, M}=2,5 \mu_{c r, N}$ to zmieniamy mnożnik $\mu_{c r, N}$ dopóki nie spełnimy warunku dla momentu zginającego. Analogicznie postępujemy w programie LTBeamN zmieniając wartość siły osiowej i ustawiając opcję z jej blokadą. W przypadku arkusza kalkulacyjnego Excel, najwygodniej jest wykorzystać wbudowaną funkcję rozwiązywania równań nieliniowych (Solver w zakładce Dane). Można ją również wywoływać z poziomu VBA. Dla schematu statycznego rozpatrywanego w przykładzie 1 otrzymujemy: $\mu_{c r, N}=1,26 \mathrm{wg}$ prezentowanej metody i 1,28 z programu MES.

Wpływ sił skupionych i zróżnicowanie miejsca przyłożenia obciążenia po wysokości przekroju można uwzględnić w sposób pokazany w pracy [5].

\section{Literatura}

[1] Weiss S.: Uwagi w sprawie kryterium stateczności w przypadku zgięcia pręta cienkościennego, Archiwum Inżynierii Lądowej, XV(3), 1969, s. 623-40.

[2] Weiss S., Giżejowski M.: Stateczność konstrukcji metalowych. Układy prętów. Arkady, Warszawa 1991.

[3] Mohri F., Brouki A., Roth J.C.: Theoretical and numerical stability analyses of unrestrained, monosymmetric thin-walled beams, Journal of Constructional Steel Research 59, 2003, pp. 63-90.

[4] Bijak R.: Ogólny przypadek zwichrzenia belek o dwuteowym przekroju bisymetrycznym podpartych widełkowo. Zeszyty Naukowe Politechniki Rzeszowskiej 276, Budownictwo i Inżynieria Środowiska 58 (3/2011/II), s. 201-208.

[5] Bijak R.: The Lateral Buckling of Simply Supported Unrestrained Bisymetric I-Shape Beams, Archives of Civil Engineering, Volume 61, Issue 4 (Dec 2015), pp. 127-140. 
[6] Stahlbau-Kalender 2009.Herausgegeben von Kuhlman U. Ernst \& Sohn, Berlin 2009.

[7] Trahair N.S., Bradford M.A., Nethercot D.A., Gardner L.: The behaviour and design of steel structures to EC3, Furth edition, Taylor \& Francis, London and New York, 2008.

[8] Stachura Z.: Ocena zwichrzenia sprężystego na podstawie interakcji symetrycznych i antysymetrycznych stanów obciążenia, Czasopismo Inżynierii Lądowej, Środowiska i Architektury - Journal of Civil Engineering, Environment And Architecture, JCEEA, Politechnika Rzeszowska,, t. XXXIII, z. 63 (1/I/16), styczeń-marzec 2016, s. 365-372, DOI: $10.7862 /$ rb.2016.43

[9] Giżejowski M., Stachura Z., Uziak J.: Elastic flexural-torsional buckling of beams and beam-columns as a basis for stability design of members with discrete rigid restraints, Proceedings SEMC 2016 Conference, Cape Town 2016.

[10] Gosowski B.: Spatial buckling of thin-walled steel-construction beam-columns with discrete bracings, Journal of Constructional Steel Research 52, 1999, pp. 293-317.

[11] Górski M., Kozłowski A.: Podatność podparcia płatwi na podporze a jej moment krytyczny, Czasopismo Inżynierii Lądowej, Środowiska i Architektury - Journal of Civil Engineering, Environment And Architecture, JCEEA, Politechnika Rzeszowska, t. XXX, z. 60 (2/13), kwiecień-czerwiec 2013, s. 99-116, DOI: 10.7862/rb.2013.20.

[12] Papp F., Rubert A., Szalai J.: DIN EN 1993-1-1-konforme integrierte Stabilitätsanalysen für 2D/3D-Stahlkonstruktionen (Teil 1), Stahlbau 83(1), 2014, s. 1-15.

[13] Boissonnade N., Greiner R., Jaspart J.P., Lindner J.: Rules for Member Stability in EN 1993-1-1, ECCS-European Convention for Constructional Steelwork, Technical Committee 8 - Stability, No. 119, 2006.

[14] LTBeamN v 1.0.3 [https://www.cticm.com/content/ltbeamn-logiciel-deversementelastique-poutres].

[15] Bijak R.: Biegedrillknicken von Trägern aus I-Profilen, w przygotowaniu do Stahlbau.

\section{LATERAL-TORSIONAL BUCKLING OF SIMPLY SUPPORTED BISYMMETRIC I-BEAM-COLUMNS}

\section{S u m m a r y}

In the paper, it was presented analytic method of determination of critical load factor for lateral-torsional buckling of unbraced columns made from bisymmetric I-sections. Analytic formulas were elaborated in a manner to make them extension of expressions used for determination of critical moment for beams under bending. Direct advantage of such approach is possibility of estimation of influence of axial force on basis of known coefficients ( $\mathrm{C} 1$ and $\mathrm{D}$ in this case). Displacement out of bending plane is estimated with use of function which is combination of symmetric and antisymmetric form of buckling. Numerical examples show good consistency of analytic results with those obtained from LTBeamN FEM software. This approach can find practical application for calculations of column with use of the general method.

Keywords: lateral-torsional buckling, beams-columns, simply supported beams, bisymmetric I-shaped beams, analytical solution

Przestano do redakcji: 20.04.2017 r.

Przyjęto do druku: 01.09.2017 r. 